\title{
EFEKTIVITAS PENGGUNAAN AMBULANCE SIAGA DESA DALAM TRANSPORTASI PRE HOSPITAL
}

\author{
The Effectiveness Of Using Village Stand By Ambulance In The Transportation \\ Pre Hospital
}

\author{
Nur Virda Amalia ${ }^{1 *}$, Ratna Puji Priyanti ${ }^{2)}$, Pepin Nahariyani ${ }^{3}$ \\ ${ }^{1,2,3}$ Prodi S1 Keperawatan Stikes Pemkab Jombang \\ Email : virda_khulwa123@gmail.com
}

\begin{abstract}
ABSTRAK
Keterbatasan kebutuhan transportasi pre hospital, baik pada masyarakat perkotaan atau pedesaan. Antara lain masyarakat di pedesaan masih sering menggunakan transportasi yang tidak layak di gunakan untuk prehospital ( sepeda motor, becak montor dll). Dengan demikian resiko untuk cidera lebih besar. Jombang sudah ada ambulance siaga desa untuk membantu masyarakat perjalanan dalam transportasi pre hospital. Tujuan penelitian ini adalah ini untuk mengetahui bagaimana efektivitas pengunaan Ambulance siaga desa terkait dengan transpotasi pre hospital.

Desain penelitian menggunakan kualitatif dengan pendekatan fenomenologi, dengan informan kepala desa, petugas kesehatan, dan saudara pengguna ambulance siaga desa dan masyarakat yang tidak menggunakan ambulance siaga desa. Metode pengambilan sample menggunakan purposive sampling. Instrumen penelitian yang utama adalah peneliti sendiri, cara pengambilan data dengan observasi, interview dan dokumentasi. Cara pengolahan data Reduction, data display, conclusion drawing / verification. Keabsahan data menggunakan triangulasi dan membercheck.

Dari hasil penelitian didapatkan tema penggunaan ambulance siaga desa dalam prehospital care di masyarakat dengan sub tema transportasi,waktu kunjungan ke rumah sakit; tema penanganan keluarga saat membawa pasien ke rumah sakit dengan sub tema pendamping,tindakan dan penanganan dan tema penggunaan ambulance dengan sub tema pengoprasian, alur penggunaan, administrasi ambulance siaga desa.

Dapat di simpulkan sesuai dengan tema dan sub tema bahwa ambulance siaga desa sudah mencakup kebutuhan masyarakat akan transportasi prehospital, namun untuk perawatan atau penanganan pre hospital dan penggunaan ambulance siaga desa belum mampu terwujud dengan baik, selain itu di karenakan administrasi yang belum jelas dan alur penggunaan ambulance siaga desa.hal lain di sebabkan kurang pelatihan dan administrasi belum baik.
\end{abstract}

Kata Kunci : Penggunaan, Ambulance Siaga Desa, Pre Hospital.

\section{ABSTRACT}

The Limitation of pre-hospital transportation needs either city community or village community, namely village community still often uses improper transportations which are used for pre-hospital (motor bike, motor rickshaw, etc). Thus the risk of injury is greater, Jombang has already had a standby ambulance for village to help community in the traveling of pre hospital transportation . The research aimed to know how the effectiveness of the using stand by ambulance for village that was associated with pre hospital care transportation.

The research design used qualitative with phenomenology approach, with village head informant, health officer, and standby ambulance for village user and community who did not use village standby ambulance. Sampling method used purposive sampling. The main research instrument was the researcher herself, data collection method used observation, interview and documentation. Data processing method were reduction, data display, conclusion drawing / verification. Data validity used triangulation and member check.

From research result was obtained that the theme of using stand by ambulance for village in pre hospital care in the community with sub theme of transportation, hospital visit time, family handling theme when bringing patient to hospital with sub theme of accompaniment, action and handling, the theme of using ambulance with sub theme of operation, the flow of usage, the administration of village standby ambulance.

It can be concluded in accordance with the theme and sub theme that village ambulance has been included community 's need about pre hospital transportation .but for maintaining or handling prehospital and using village standby ambulance has not been able to actualize well, besides because 
of being unclear administration and the flow of stand by ambulance for village, other things are caused by the lack of training and administration hasn't been good.

Keywords: Using Village Standby Ambulance, Pre Hospital.

\section{PENDAHULUAN}

Masyarakat dipedesaan sering kesulitan untuk mendapat alat tranportasi untuk bisa membawa keluarganya ke pelayanan kesehatan baik itu, pelayanan kesehatan yang dekat ataupun jauh. Hal ini disebabkan tidak semua masyarakat pedesaan mempunyai mobil atau transportasi yang bisa memberikan kenyamanan dan kemanan bagi pasien tersebut saat di bawa ke pelayanan kesehatan, sekarang telah adanya fasilitas kendaraan yang telah tersedia yang diberikan oleh pemerintah kabupaten Jombang.

Masyarakat dipedesaan sering kali membawa keluarganya kerumah sakit hanya dengan transportasi seadanya misalnya (sepeda motor dan becak). Mereka sadar bahwa membawa pasien dengan transportasi sepeda motor dapat mengakibatakan resiko jatuh, tetapi masih dilakukan karena keterbatasan yang transportasi yang dimiliki selain itu, masih banyak pasien dari pedesaan meninggal di tempat dan saat akan menuju rumah sakit karna keterlambatan keluarga untuk membawa kerumah sakit.

Berdasarkan data Dinkes (2015) angka kematian murni atau Nett death rate (NDR) di rumah sakit adalah angka kematian $\geq 48$ jam setelah di rawat untuk tiap-tiap 1.000 pasien keluar rumah sakit. Angka kematian murni atau NDR tahun 2015 sebesar 30.5 per 1000 pasien keluar. Artinya setiap 1.000 pasien keluar hidup maupun keluar mati rumah sakit, terdapat 31 pasien keluar mati yang sebelumnya sudah di rawat $\geq 48$ jam (2 hari) (Dinkes.2015).

Sudah diperkirakan lebih dari 11.000 pasien kritis membutuhkan pemindahan pasien antar rumah sakit setiap tahunya (intensive care society 1997;Mackenzie et al.1997). Pemindahan pasien antar rumah sakit menyebabkan pasien kritis terpajan oleh resiko esensial (Markakis et al.2006). Walaupun jumlah tranfer pasien antar rumah sakit sangat besar, namun ketersediaan peralatan masih buruk dan sering kali menimbulkan komplikasi yang berpotensi serius (Intensive Care Society 1997;Bion Et Al.1998). Kualitas dan hasil akhir tranfer pasien ini sangat tergantung pada pengalaman tim transfer, persiapan klinis secar teliti dan fasilitas pemantauan yang adekuat (Tan, 1997 ). Angka mortalitas selama pemindahan pasien sanggat rendah $(<1 \%)$ (Hind \& Watson 1996).

Saat ini pemerintah Kabupaten Jombang telah menjawab tantangan akan pelayanan kesehatan primer, maka dengan ini pemerintah Kabupaten Jombang mengadakan mobil ambulance siaga desa. Proses pengadaan kendaraan tersebut berpedoman pada Peraturan Presiden Nomor 54 tahun 2010 tentang pedoman pengadaan barang/jasa pemerintah sebagaimana telah diubah dengan Perpres Nomor 35 tahun 2011. Lalu diubah dengan Perpres Nomor 70 tahun 2013 yaitu dengan penunjukkan langsung harga E-Cataloque LKPP Sistem E-Purchasing dengan merk Suzuki Arena GL Nik 2014 ambulance standart. Ambulance siaga desa sendiri di rancang sebagai armada yang serbaguna dan multifungsi untuk memenuhi kebutuhan masyarakat sekitar antara lain untuk membantu masyarakat miskin yang membutuhkan tranportasi ke pelayanan kesehatan setempat

Ambulance siaga memiliki fungsi untuk mengantarkan masyarakat yang mengalami ganguan kesehatan untuk menuju rumah sakit. Untuk sopir ambulance siaga desa tidak di tentukan secara pasti oleh pihak desa tersebut. Jadi untuk sopir ambulance siaga bisa dari perangkat desa yang pilih atau bisa dari pihak keluarga pasien itu sendiri, untuk itu peneliti mengevaluasi pemakaian ambulance siaga desa maka peneliti ini di maksud dengan tujuan mengetahui efektivitas pengunaan ambulance siaga desa dalam transportasi pre hospital di Jombang.

\section{METODE PENELITIAN}

Metode penelitian kualitatif dengan pendekatan fenomenologi menurut Creswell (dalam Sugiyono, 2014) adalah salah satu jenis pendekatan kualitatif dimana dalam pendekatan jenis ini peneliti melakukan sebuah observasi kepada partisipan untuk mengetahui fenomena - fenomena yang terjadi dalam partisipan tersebut. Hal tersebut dilakukan sebagai bentuk pengumpulan data oleh peneliti yang kemudian diolah untuk menemukan makna dari apa yang telah di kemukakan oleh partisipan. Instrumen 
dalam penelitian ini adalah peneliti sendiri. Subjek pada penelitian ini sebanyak 6 orang mencakup 1 kepala desa, 1 sopir sebagai subjek penelitian dengan triagulasi kepala desa dan sopir.1 masyarakat desa yang pernah menggunakan ambulance siaga desa, 1 masyarakat desa yang tidak pernah menggunakan ambulance siaga desa dan 1 tokoh masyarakat bidan desa dengan teknik puposive sampling. Teknik pengumpulan data menggunakan teknik wawancara dan observasi.

Penelitian ini dilaksanakan pada tanggal 28 Maret - 29 April 2016, waktu pelaksanaan dilakukan pada pagi, siang dan sore hari di salah satu desa di Jombang dan dirumah pasien. Teknik analisis data: Reduksi data, Penyajian data, Conclusion drawing/verification. Teknik pengujian keabsahan data, menggunakan Member check dan Triangulasi

\section{HASIL DAN PEMBAHASAN}

Pada bab ini menjelaskan tentang bagaimana perasaan pasien GGK yang menjalani hemodialisa. Hasil penelitian menghasilkan 3 tema utama yang memberikan suatu gambaran berbagai perasaan pasien yang menjalani terapi hemodialisa.

\section{Deskripsi informan penelitian}

1. Informan R01

Informan ini Setiap harinya berkerja sebagai petani tetapi setalah sakit hanya Ibu Rumah Tangga karna sekarang terdapat luka di kakinya dan jika berjalan harus menggunakan alat perangga dan harus control ke rumah sakit setiap minggu.

2. Informan R02

Informan kedua ini sering menggunakan ambulance siaga desa karna sering di Rujuk ke RSUD Jombang.

3. Informan R03

Informan ketiga merupakan tidak mau menggunakan ambulance siaga desa karna trauma yang pernah di alami oleh Informan RO3.

4. Informan $\mathrm{S} 04$

Informan keempat ini Setiap harinya Informan S04 bekerja sebagai Sopir ambulance siaga desa.

5. Informan P05

Informan kelima ini adalah sebagai kepala desa.

6. Informan B06

Informan keenam ini sebagai bidan desa.

Deskripsi Hasil Penelitian
A. Penggunaan Ambulance Siaga Desa dalam Prehospital Care di Masyarakat

Berdasarkan hasil wawancara mengenai apa penyebab Sering masyarakat desa L mengalami kesulitan untuk menggantar keluarganya kerumah sakit karna tidak mempunyai transportasi (mobil) untuk membawa kerumah sakit. Sering kali masyarakat desa L membawa keluarga yang sakit kerumah sakit menggunakan becak montor (bentor) / sepeda motor. Saat belum adanya mobil ambulance siaga desa.

\section{1) Transportasi}

Dari hasil penelitian didapatkan hasil bahwa penggunaan ambulance siaga desa sering di gunakan untuk mengantar masyarakat desa latsari untuk menuju ke rumah sakit baik itu untuk rujukan dari bidan desa ataupun kontrol.

Informan R01 menyatakan

" pertama kali di bonceng naik (becak motor)karena belum tau nomer telfon sopir ambulance desa tetapi saat pulang dari rumah sakit R01 menggunakan ambulance desa. Waktu itu naik bentor (becak motor) sampai perempatan saja karena bentor tidak di perbolehkan masuk jombang kota akhirnya saya di bonceng naik sepeda motor naik saya menahan sakit di kaki saya karena di buat gerak sedikit sudah sakit"

Selanjutnya informan R02 menjawab sebagai berikut:

" langsung secara spontan waktu itu saat keadaan hamil 6 bulan mungkin.waktu rujukan ke tugu di antar bu lilik karna saya mempunyai KIS . waktu itu bu lilik ikut mengantarkan priksa dan mengantakan saya rujuk di RSUD memakai mobil desa "

Selain itu informan R03 memberikan pendapatnya mengenai penggunaan ambulance siaga desa sebagai berikut:

"sudah saya tidak berfikir ke siaga karna saya juga tidak igin mengendarainya. Saya menyuruh tetangga saya untuk mengantarkan dan di bonceng 3".

(kenapa ibu tidak mau mengunakan ambulance siaga desa?)

"jadi saya itu jika mengendarai ambulance siaga desa terbayang-bayang akan rintihan adik saya"

2) Waktu kunjungan Rumah Sakit

Saat di tanya berapa kali penggunaan ambulance siaga desa

Berikut pernyataan dari informan R01 : 
"dari Agustus sudah ada 7 bulan lebihkan, 1 bulan 4 kali setiap hari jumat"

Berikut pernyataan dari informan R02

“ Dua kali kalo gak salah pendarahan sama yang bayiku meninggal dulu itu memakai ambulance itu untuk ke RSUD Jombang,kalo RSK Mojowarno sudah 3 kali "

" sama menggunakan angkutan umum 1 kali saat itu waktu control di RSUD Jombang “

Berikut pernyataan dari informan R03 :

"sudah saya tidak berfikir ke siaga karna saya juga tidak igin mengendarainya. Saya menyuruh tetangga saya untuk mengantarkan dan di bonceng 3".

Menurut teori dari (Perda ABPD Tahun 2015 ) penggunaan transportasi ambulance siaga desa memang di modif khusus agar bisa di gunakan multifungsi oleh masyarakat.

\section{B. Penangganan Keluarga saat membawa pasien ke rumah sakit}

\section{1) Pendamping}

Dari hasil wawancara yang peneliti menanyakan Dengan siapa keluarga membawa pasien yang sakit menuju rumah sakit, keluarga sendiri atau dengan tenaga kesehatan yang berada di desa L kabupaten Jombang

Berikut pernyataan dari informan R01 :

"sama anak saya mbak"

"keluarga ya bergilir mbak. anak banyak tapi paling sering ya cucunya yang perawat itu”

Berikut pernyataan dari informan R02 :

“ ya dengan suami saya jika kerja ya saya telfon dan langsung pulang untuk mengantar saya"

Berikut pernyataan dari informan S04

"kebanyakn orang sini di antar keluarga sendiri mbak,"

Berikut pernyataan dari informan B06 :

"Di sini kalo orang sakit brangkat sendiri mbak, seharusnya kan prawatnya. Tapi ya gak tau mbak perawat nya kan sudah lama di sini dari karakter masing-masing perawatnya kayak gitu.

Tapi kalo kasus persalinan ya wajib bidan desanya menggantarkan ke rumah sakit"

Efektifitas respone time bergantung pada 3 faktor utama di pre hospital stage yang berperan terhadap kualitas hidup penderita nantinya yaitu : a. Siapa penolong pertamanya

b. Berapa lama di temukannya penderita

c. Kecepatan meminta bantuan pertolongan. (Bayu laksono,2015)

Dari hasil wawancara oleh ketiga informan di atas bahwa masyarakat sering membawa keluarga yang sakit tanpa memanngil tenaga kesahatan sekitar. Menurut teori efektifitas respon time tergantung pada siapa penolong pertamanya yang nantinya akan berperan pada kualitas hidup penderita nantinya.

Dari hasil wawancara peneliti mendapatkan fakta bahwa masyarakat desa L tidak mengetahui bagaimana cara penanganan pertama pada pasien yang sakit. Seperti keterangan hasil wawancara dengan keluarga di bawah ini :

Berikut pernyataan dari informan R01 :

“ di jalan tidak lakukan apa-apa mbak kan naik bentor, Cuma sebelumnya di bawa ke rumah sakit di lukanya di bersihkan saja

Berikut pernyataan dari informan R02 :

" tidak di lakukan apa-apakan mbak hanya di tidurkan saja"

cara penanganan oleh sopir

tindakkan apa yang pernah anda berikan untuk pasien

Berikut pernyataan dari informan S04 :

"Penanganan se enggak misal paruparu saya pasang oksigen saja mbak kebanyakkan pasiennya paru-paru. Pertama saya pasang saya stel ke pasien lalu pasien saya Tanya sudah enakkan gak kalo gak enak saya besarkan klo enak saya kecilkan tergantung kondisi orang yang merasakan, sudah enak ya saya pasang"

cara penanganan oleh tenaga medis

Berikut pernyataan dari informan B06:

"ya kita mengantispasi aja misal orang sakit ya mempertahankan kondisi supaya pasien cepat mendapatkan pertolongan. Kalo untuk persalinan kita berjaga-jaga apabila nantik bersalin di jalan itu ya alat obat dan lain sebagainya itu harus $d$ siapkan"

Bapaknya pernah di ajari apa saja sama bidan desa kayak misal penanganan pasien

Berikut pernyataan dari informan S04 :

" waktu itu gini mbak kan ada mbak pelatihan di RSK Mojowarno waktu itu ada setiap sopir mobil siaga mojowarnodi suruh datang dan pelatihan di situ ya cara-cara memasukkan pasien ke grobak tapi saya 
sudah tau semua saya pelajari sudah bisa itu, memang ada pelatihan di rumah sakit mojowarno ya istilahnya pertolongan yang darurat saja"

Biasanya pertolongan apa yang bapaknya berikan

Berikut pernyataan dari informan S04 :

"iya itu saja pokok e sekiranya tapi kebanyakan penyakit itu aja mbak, saya hanya berusaha secepatnya menuju UGD biar orangnya cepet tertolong "

Bahwa pertolongan pertama seharunya orang awam yang terlatih dengan dukungan pelayanan ambulan gawat darurat 24 jam. Ironisnya penolong pertama di wilayah Indonesia sampai saat ini adalah orang awam yang tidak terlatih dan minim pengetahuan tentang kemampuan pertolongan bagi penderita gawat darurat teori ini di perjelas oleh (laksono bayu, 2015)

Menurut hasil wawancara diatas bahwa masyarakat desa L tidak tau harus melakukan tindakan apa sehingga saat mengantar keluarganya yang sakit mereka hanya sekedar mengantar saja tidak melakukan tindakan apa-apa, kebanyakan jika keluarganya merasa kesakitan mreka hanya menyuruh untuk tetap bertahan.

\section{Alur Penggunaan Ambulance}

\section{1) Pengoprasian Ambulance Siaga Desa}

Berdasarkan hasil wawancara mengenai Siapa yang mengoprasikan Untuk supir ambulance siaga desa sendiri di desa L kabupaten Jombang. berikut pernyataan dari informan P05:

"dari LPMD supirnya tetep satu saya hanya dari LPMD saja. Biasanya kalo supir lain kan tidak tau untuk mengontrol kan ada habis meter kan gak tau karna kita untuk kroscek service oli itu sanggat menentukan makanya saya pakek sopir satu kalo srabutan itu nanti bahaya untuk perawatan semuanyakan nanti bahaya"

berikut pernyataan dari informan S04

"3 tahun saya jadi sopir siaga desa "

\section{2) Alur Penggunan Ambulance Siaga Desa}

Berdasarkan hasil wawancara mengenai penggunaan ambulance siaga desa Informan S04 sering menggantar masyarakat desa L menggunakan ambulance siaga desa. Berikut pernyataan dari informan R01: "orang udah tau lah di rapatkan dibalai desa bahwa mobil ini untuk masyarakat desa Latsari siapa yang membutuhkan untuk menghubungi saya, jadi saya itu melayani satu kelurahan desa Latsari. Jadi semua orang udah tau kan nomer saya sudah $d$ cantumkan di balai desa. Jadi saya gak ngasih tiba-tiba orang ngebel, Tolong antar saya ke jombang antar saya ke Surabaya tolong di ambil orang ini saya tadi baru aja ambil orang di mojowarno.

Satu minggu full mbak, Jamnya itu gak tentu mbak jadi ya sewaktu-waktu jadi saya 24 jam harus siap. Dibel langsung brangkat walaupun malam kayak apa ya saya langsung brangkat, Sudah saya data itu jadi mulai mobil siaga desa datang itu. Saya punya catatan buku kecil nama pasien, rujukan, bidan siapa yang mengantar dan jarak tempuh sini sama rumah sakit itu slalu saya tulis kok

Sini pare jarak tempuh ada $25 \mathrm{Km} / \mathrm{Jam}$ dari rumah sampek pare kalo cepat setenggah jam"

Berdasarkan hasil wawancara mengenai penggunaan ambulance siaga desa Informan P05 sering mengetahui Informan S04 menggantar masyarakat desa Latsari menggunakan ambulance siaga desa. Seperti pemaparan yang di sampaikan oleh informan P05 sebagai berikut:

" 1 Minggu bisa di gunakan 6-7 kali, tiap hari biasanya 2-3 kali di gunakan untuk mengantar orang sakit. Ada kalanya pengajian itu biasanya hari minggu untuk muslimat tapi yang pasti itu untu pasien menggatar ke rumah sakit "

Pernyataan- pernyataan di atas sesuai dengan perda ABPD Tahun (2015) yang menjawab tujuan khusus dari ambulance siaga desa yaitu " mempercepat pelayanan kegawat darurat masalah kesehatan, bencana serta kesiapsiagaan mengatasi masalah kesehatan yang terjadi atau mungkin terjadi dan menekan angka kematian ibu dan bayi

Teori yang sudah tertulis diatas ternyata sama dengan fakta yang ada di masyarakat bahwa ambulance siaga desa di gunakan untuk mempercepat pelayanan kegawat darurat masalah kesehatan, bencana serta kesiapsiagaan mengatasi masalah kesehatan yang terjadi atau mungkin terjadi dan menekan angka kematian ibu dan bayi

3) Administrasi Ambulance Siaga Desa 
Seperti pemaparan yang di sampaikan oleh beberapa informan saat di Tanya Bagaimana proses administrasinya penggunaan ambulance siaga desa menurut keluarga adalah sebagai berikut:

Berikut pernyataan dari informan R01 :

"1 bulan 400 setiap jumat ke rumah sakit, rumah sakitnya gak bayar Cuma mobil kan 100 trus mbak setiap jumat,Jadi setiap pengunaan mobil desa 100 kalo gabung ya 5050 masih ada keringanan tapi kalo gak ya 100. Ibuk dari bulan agustus mbak sampai sekarang total 1700 lebih kayaknya mbak. Tapi peserta kantor tidak membayar karna kan fasilitas kantor tapi kalo masyarakat umum kan mesti memberi berapa cuman klao saya segitu ya kemahalan mbak, kalo naik mobil pribadi orang kan mesti nambah 50 ini “

Berikut pernyataan dari informan R02 :

"di RSK Mojowarno naik sepeda motor kan deket mbak maklum ekonominya kurang mbak jika naik ambulance siaga kan sudah Ten mowar nete sepeda celak maklum ekonominya kan kirang lak nete ambulance kan est ketok piro mbak, Est gak usah ngekek I ngeh a kasaran wong gak duwe ngeh a lak kulo mboten saget mbak isin lah ngeh a wedi di rasani wong wong Ngalah I kulo gonceng mawon niki kulo tanglet I kiat ngeh kulo budal I lak mboten kiat kulo ngeh mboten wanton mbak"

Banyak Informan dalam penelitian ini sering mengeluh mengenai tarif adminitrasi penggunaan ambulance siaga desa sendiri. Karena administrasinya sendiri menurut imforman memberatkan masyarakat,.

Oleh karena itu sebaiknya administrasi penggunaan ambulance siaga desa harus di perbaiki karena banyak informan yang mengeluh dengan administrasi penggunaan ambulance siaga desa sehingga masyarkat enggan menggunakan transportasi ambulance siaga desa sebagai sarana transportasi pre hospital care. Ada salah satu informan lebih memilih mengantarkan keluarganya yang sakit menggunakan sepeda motor dan tidak menghiraukan resiko yang ada karena ketidak adaan biaya.

\section{4) Respon dan Pengalaman}

Dari hasil wawancara yang peneliti dapat di desa L kabupaten Jombang. tentang pengalaman saat melakukan tindakan pre hospital care dan saat itu belum sampai ke rumah sakit: berikut pernyataan dari informan B06

"belum pernah"(B06)

Jika ada pasien kritis dan harus di bawa ke rumah sakit bagaimana tindakkan bapak saat membawa ambulance.

berikut pernyataan dari informan S04

"ya kita berusaha secepat mungkin mbak.

Kecepatan ya cepat bener.saya pasang sirene lalu saya nyalakan dan rata-rata masyarakat memberikan jalan saya jarak tempuh “

Pernah tidak ada pasien yang meninggal saat perjalanan ke rumah sakit

berikut pernyataan dari informan $\mathrm{S} 04$

"gak pernah sih ya mungkin selang beberapa menit aja. 2 kasus jadi pulang ambil pasien di rumah sakit masuk rumah tiba di rumah meninggal trus pernah juga gitu dari rumah sakit tak antar pulang meninggal karna dokter tidak sanggup jadi pihak keluarga mintak di bawa pulang hanya 2 kali aja eh 3 kali yang ngambil dari rumah sakit 2 kali ambil dari rumah 1 kali . waktu dengan pasien strok pasien jatuh dari kamar mandi dan saya di telfon oleh pihak keluarga dengan kondisi pasien pingsan. Waktu itu p selang 15 menit saya masukkan saya angkat saya bawa gerobak ke mobil saya parkirkan mobilnya tau-tau di kabari keluarga pasien sudah meninggal "

Membunyikan sirine juga di dukung dengan Sebagaimana bunyi UU No 22 Tahun 2009 Pasal 135: Kendaraan yang mendapat hak utama sebagaimana dimaksud dalam Pasal 134 harus dikawal oleh petugas Kepolisian Negara Republik Indonesia dan/atau menggunakan isyarat lampu merah atau biru dan bunyi sirene. Respon ini harus ditunjukkan dengan menghidupkan alat peringatan (warning device) berupa sirene dan lampu rotator. Risiko kecelakaan tetap ada, sehingga pengemudi tetap harus memiliki kewaspadaan tinggi, mempedulikan keselamatan pengemudi lain dan tidak ceroboh.

Hal ini sesuai dengan teori (Oktafiani E,2013) Pelayanan emergensi pra-hospital merupakan pelayanan yang di berikan oleh tim ambulance sebagai transportasi emergensi sebelum pasien tiba dan di terima oleh rumah sakit. Pelayanan emergnensi pre-hospital membutuhkan kecepatan dan ketepatan untuk meminimalisir resiko pasien. Sehingga durasi response time 
menjadi indikator penting dalam pelayanan emergensi pre-hospital

Pada teori pelayanan pre-hospital membutuhkan kecepatan dan ketepatan untuk meminimalisir resiko pasien. Informan S04 sudah berusaha melajukan dengan cepat ambulance siaga desa agar bisa sampai di Rumah sakit secepat mungkin agar pasien dapat tertolong.

\section{5) Perlengkapan}

Dari hasil wawancara yang peneliti dapat bahwa kelengkapan alat diambulance siaga desa kurang memadai dan ada alat yang tidak slalu terpasang di ambulance siaga desa karna ada masyarakat lain yang membutuhkan sehingga di pinjamkan ke masyarakat setempat.

Apa saja kelengkapan alat yang ada di ambulance siaga desa

Berikut pernyataan dari informan $\mathrm{P} 05$ :

" tabung oksigen, tabung pemadam, lampu sirene, brangkat, tandu, tempat cuci tangan"

Biasanya yang pasti dan harus ada di dalam ambulance siaga desa itu apa

Berikut pernyataan dari informan S04 :

" yang pasti itu ya masker itu mbak saya slalu ada "

Menurut teori (Boswick, 2012). Ambulance merupakan alat transportasi gawat darurat yang telah di kembangkan untuk memberikan ruang kerja dan peralatan yang di sertakan untuk menyelamatkan nyawa pasien. Standar rencangannya telah di kembangkan oleh ' National Academy of Sciences' dan di beri mandate untuk membeli mobil ini dengan dana faderal. Komite Trauma ' American Collage of Surgeon' telah mebuat daftar peralatan bagi peralatan penyongkong minimum yang bisa dibawa ambulance untuk memberikan perawatan gawat darurat.

Alat-alat yang harus ada di dalam ambulance menurut teori (PERSI JATIM, 2016) Alat - alat yang digunakan untuk pertolongan di lokasi kejadian meliputi antara lain tas tangan yang berisi suction portable, airway dan intubasi, cairan infuse, obat resusitasi, portable defib, backboard. Di dalam ambulance siaga desa sebagian sudah ada dan sebagian belum ada. Dan kurangnya pengetahuan sopir personil ambulance siaga desa yang faham akan tindakan gawat darurat dan ikut menggantar pasien ke rumah sakit.

Kurangnya pengetahuan sopir ambulance siaga desa dan tim ambulance siaga desa yang dapat membantu proses pre hospital care di wilayah jombang. dan tidak di dukung oleh alat-alat yang di butuhkan saat penanganan pre hospital care sehingga kurangnya tidak bisa membantu pasien yang membutuhkan alat itu segera.

\section{Masyarakat yang tidak mau menggunakan ambulance siaga desa}

Berdasarkan hasil wawancara mengenai penggunaan ambulance siaga desa Informan R03 tidak menggunakan ambulance siaga desa karna trauma perasaan tidak menyenangkan. Berikut pernyatan dari informan R03 :

"jadi saya kalo naik ambulance siaga desa ngeri inggat rintihan suara kesakitan adek saya meski saya musyawarah desa yang lain naik mobil siaga saya lebih baik naik sepeda motor sendiri ngikut di belakangnya mobil siaga, kulo mending numpak pedah dewe ngetotne burine mobil siaga, kadang jika perkumpulan di ngoro mojowarno kecamatan kadang kan di antar ambulance orang banyak,jadi saya tidak nyaman jika harus naik ambulance meskipun ambulance bukan tempat orang mati kan tapi saya seaka-akan mengingat kejadian adek saya, terus resah eh mbak kayak adek saya merintih kesakitan trus, dari pada sedih,kan lebih baik saya tidak menaikki ambulance" Dengan siapa Kalo naik sepeda ke rumah sakit

"kemaren waktu di bonceng 3 dengan siapa bu "

"ya waktu itu di bonceng 3 apa anda tidak takut jatuh

Tidak mbak. Waktu itu saya goncengnya pelan kok mbak"

Jarak tempuh rumah dengan rumah sakit "jarak e jauh mbak dari rumah ke bareng 4 km balik lagi $4 \mathrm{~km}$ jadi $8 \mathrm{~km}$ lalu ke desa $\mathrm{K}$ setengah $\mathrm{km}$ lalu kers mojowarno $3 \mathrm{~km} \mathrm{ya}$ $11,5 \mathrm{~km} \mathrm{mbg}$ ".

Jadi tidak pernah naik ambulance siaga desa, " iya sekali saja mbak waktu itu saya di bohonggi waktu itu ada acara jambore di ngoro"

\section{E. Ringkasan Kesimpulan dari Setiap Pertanyaan}


(1) Penggunaan Ambulance Siaga Desa dalam Prehospital di Masyarakat

Dari wawancara diatas didapatkan kesimpulan bahwa Penggunaan ambulance siaga desa dalam prehospital care di masyarakat desa L kabupaten Jombang sanggat aktif bahkan hampir setiap hari ambulance siaga desa slalu digunakan untuk mengantar orang sakit baik itu untuk kontrol ataupun proses transportasi prehospital, biasanya jika hari minggu saja di gunakan untuk pengajian

(2) Bagaimana Penanganan Keluarga Saat Membawa Pasien ke Rumah Sakit

Dari wawancara diatas didapatkan kesimpulan bahwa bahwa Seringnya masyarakat di desa L jika membawa keluarga yang sakit tidak meminta bantuan kepada tenaga medis setempat, karena masyarakat desa L menganggap bahwa tenaga medis di desa L tidak ada saat mreka membutuhkan dan jika harus memanggil tenaga medis masyarakat menganggap terlalu lama, Mereka hanya inggin keluarganya segera di tangani oleh pihak rumah sakit. Dan kurangnya penyuluhan kesehatan kepada masyarakat sehingga masyarakat mengabaikan tenaga medis setempat.

Masyarakat desa L tidak mengetahui harus melakukan tindakan apa sehingga saat mengantar keluarganya yang sakit mereka hanya sekedar mengantar saja tidak melakukan tindakan apa-apa, kebanyakan jika keluarganya merasa kesakitan mereka hanya menyuruh untuk tetap bertahan.

(3) Bagaimana Pengoprasian dan Alur Penggunaan Ambuance Siaga Desa

Fakta yang ada di masyarakat bahwa ambulance siaga desa di gunakan untuk mempercepat pelayanan kegawat darurat masalah kesehatan, bencana serta kesiapsiagaan mengatasi masalah kesehatan yang terjadi atau mungkin terjadi dan menekan angka kematian ibu dan bayi

Administrasi penggunaan ambulance siaga desa juga harus di perbaiki karena banyak informan yang mengeluh dengan administrasi penggunaan ambulance siaga desa sehingga masyarkat enggan menggunakan transportasi ambulance siaga desa sebagai sarana transportasi pre hospital. Didalam ambulance siaga desa tidak di dukung oleh alat-alat yang di butuhkan saat penanganan pre hospital care sehingga kurang efektif untuk membantu pasien yang membutuhkan alat itu segera.

\section{Kesimpulan}

Berdasarkan hasil penelitian maka dapat disimpulkan bahwa :

1. Memahami Penggunaan Ambulance Siaga Desa

Penggunaan transportasi ambulance siaga desa sanggat berguna untuk masyarakat di wilayah desa latsari karna masyarakat di sana sering menggunakan transportasi ambulance siaga desa untuk mengantar keluarganya yang sedang sakit menuju rumah sakit, kontrol ke rumah sakit ataupun rujukan ke rumah sakit. Masyarakat sering menggeluhkan mengenai biaya administrasi penggunaan ambulance siaga desa.

2. Bagaimana Penanganan Keluarga Saat Membawa Pasien ke Rumah Sakit

Masyarakat di desa Latsari jika membawa keluarga yang sakit tidak meminta bantuan kepada tenaga medis setempat, karna kurangnya penyuluhan kesehatan kepada masyarakat sehingga masyarakat mengabaikan tenaga medis setempat. Masyarakat desa Latsari tidak tau harus melakukan tindakan apa sehingga saat mengantar keluarganya yang sakit mereka hanya sekedar mengantar saja tidak melakukan tindakan apa-apa, kebanyakan jika keluarganya merasa kesakitan mreka hanya menyuruh untuk tetap bertahan.

3. Bagaimana Pengoprasian Dan Alur Penggunaan Ambulance Siaga Desa

Administrasi penggunaan ambulance siaga desa juga harus di perbaiki karena banyak informan yang mengeluh dengan administrasi penggunaan ambulance siaga desa sehingga masyarkat enggan menggunakan transportasi ambulance siaga desa sebagai sarana transportasi pre hospital. Didalam ambulance siaga desa tidak di dukung oleh alat-alat yang di butuhkan saat penanganan pre hospital sehingga kurangnya bisa membantu pasien yang membutuhkan alat itu segera.

\section{Saran}

a. Bagi pemerintah dan Daerah Lokal Diharapkan pemerintah menambahkan sarana alat emergency di setiap ambulance 
siaga desa agar dapat membantu proses pre hospital care.

b. Bagi keluarga

Penelitian ini diharapkan dapat menjadi acuan keluarga guna mengembangkan pertolongan pertama pada pasien gawat darurat.

c. Bagi perawat

Diharapkan perawat dan calon perawat mampu memberikan penyuluhan langsung ke masyarakat agar warga sadar akan sikap yang sudah dilakukan pada orang sakit.

d. Bagi Desa

Diharapkan perangkat desa tanggap dan mau melaporkan sesuai dengan wadahnya, setiap ada kejadian aneh yang terjadi di tengahtengah masyarakat misalnya terdapat gangguan jiwa yang meresahkan warga.

\section{DAFTAR PUSTAKA}

Persi ii jawa timur. 2016 . Emergency Ambulance Service Training.

Bidang diklat PPNI jawa timur. 2016 . Materi Pelatihan Basic Trauma Cardiac Life Support

Nursalam. 2016. Metode Penelitian Ilmu Keperawatan : Pendekatan Praktis Edisi 4. Jakarta: Salemba Medika

Prof .Dr. H.Tabrani Rab.2007. Agenda Gawat Darurat (critical care) jilid 1. Bandung. PT Alumni

Dinas Kesehatan Kabupaten Jombang. 2015. Profil Kesehatan Kabupaten Jombang 2015 : Jombang.

Härtl, Roger, et al.2006." Direct Transport Within An Organized State Trauma System Reduces Mortality in Patients With Severe Traumatic Brain Injury." Journal of Trauma and Acute Care Surgery 60.6 (2006): 1250-1256. Diakses pada tanggal 5 januari 2017

Sugiyono. 2015. Memahami

penelitian Kualitatif. Bandung: Alfabeta

Pitt E, A Pusponegoro. 2005 Emergency Medicine jurnal: Prehospital Care in Indonesia. Prehospital care. Online Pitt, E., and A. Pusponegoro. "Prehospital care in Indonesia." Emergency medicine journal 22.2 (2005): 144-147.
Bapenas. 2015. Pembangunan desa yang sehat dan makmur. Online http://www.bappenas.go.id/index.php/dow nload_file/view/10866/3188/ diakses pada tanggal 6 januari 2017

Tan, Pek Ghe, et al. "Review article: Prehospital fluid management in traumatic brain injury." Emergency Medicine Australasia $23.6 \quad$ (2011): 665-676. https://scholar.google.co.id/scholar?q=tan+ prehospital\&btnG $=\& \mathrm{hl}=\mathrm{id} \&$ as_sdt $=0 \% 2 \mathrm{C}$ 5. Diakses pada tanggal 6 januari 2017

Peleg K, Pliskin JS. A geographic information system simulation model of EMS: Reducing Ambulance Respon Time. Trauma and Emergency medicine research. 2004;164-70. Online https://scholar.google.co.id/scholar?q=Pele $\mathrm{g}+\mathrm{K} \% 2 \mathrm{C}+\mathrm{Pliskin}+\mathrm{JS} .+\mathrm{A}+\mathrm{geographic}+\mathrm{inf}$ ormation+system+simulation+model+of+ EMS\%3A+Reducing+Ambulance+Respon +Time.+Trauma+and+Emergency+medici ne+research.+2004\%3B $164-$ $70 \& b t n G=\& h l=i d \& a s \_s d t=0 \% 2 \mathrm{C} 5$

Diakses pada tanggal 9 januari 2017

Lieser \& Alexis. 2009. Perspective om emergengy medical services in Bali. Western journal of emergency medicine. Department of emergency medicine: UC Irvine

Laksono bayu. 2015. Prehosital online https://es.scribd.com/doc/123367264/pre -hospital. diakses pada tanggal 10 januari 2017

Jhon A. Boswick. 2012. Perawatan Gawat Darurat . Jakarta . buku kedokteran EGC

Dinkes wonosobo. 2014. Prosedur pengoprasian ambulance. Online http://dinkes.wonosobokab.go.id/wpcontent/uploads/2014/10/PROSEDURPENGOPERASIAN-AMBULANCE.docx. diakses pada tanggal 5 february 2017 